http://dx.doi.org/10.18675/1981-8106.vol25.n49.p340-356

\title{
A inclusão escolar no município de Araras: condições e perspectivas ${ }^{1}$
}

\section{Schoolar inclusion in Araras: conditions and prospects}

\section{La inclusión escolar en el municipio de Araras: condiciones y perspectivas}

\author{
Josiele Giovana de Lucca' \\ Fernanda Vilhena Mafra Bazon" \\ Daniele Lozano"II \\ 'Universidade Federal de São Carlos (UFSCar), São Carlos, São Paulo - Brasil. E-mail: \\ josieledelucca@gmail.com \\ "Universidade Federal de São Carlos (UFSCar), São Carlos, São Paulo - Brasil. E-mail: \\ febazonccaufscar@gmail.com \\ "'Universidade Federal de São Carlos (UFSCar), São Carlos, São Paulo - Brasil. E-mail: \\ Iz.daniele@gmail.com
}

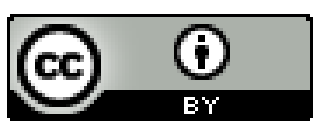

Educação: teoria e prática, Rio Claro, SP, Brasil - eISSN: 1981-8106

Está licenciada sob Licença Creative Common

\section{Resumo}

Este trabalho teve como foco o entendimento das condições e perspectivas de inclusão no município de Araras, a partir dos relatos de professores, gestores e pibidianos. A coleta de dados foi realizada por meio da aplicação de questionários e entrevistas semiestruturadas, buscando a compreensão das concepções dos agentes educacionais no que tange ao processo inclusivo, e de como essas concepções influenciam suas práticas pedagógicas. O estudo pauta-se na abordagem qualitativa de pesquisa em educação. A busca pelo entendimento da realidade local é de grande importância para nortear as ações e práticas educacionais que possam colaborar na efetivação do processo inclusivo, com vistas à construção de uma escola democrática. Constatou-se que a formação docente ainda é um ponto nodal na efetivação desse processo, sendo que as concepções e práticas educacionais apontam para a não responsabilização do professor pelas atividades pedagógicas com alunos com necessidades

\footnotetext{
${ }^{1}$ Agradecemos à FAPESP e ao CNPq
} 
educacionais especiais. Por fim, verificou-se que o Pibid se configura como espaço potencial para discussões e reflexões sobre as ações e concepções inclusivas.

Palavras-chave: Inclusão escolar; Necessidades Educacionais Especiais; Educação Especial.

\begin{abstract}
This study seeks the understanding of the conditions and prospects of inclusion in schools of Araras, based on the reports of teachers, managers and students of Pibid. The collect of the data was performed by the application of questionnaires and semi-structured interviews, seeking the understanding of the concepts of educational agents in connection with the inclusive process, and how these concepts influence their pedagogical practices. The study relied on the qualitative approach to research in education. The search for understanding the local reality is of great importance to guide the actions and educational practices that can collaborate in the inclusive process, seeking the construction of a democratic school. It was found that teacher formation is still a nodal point in the effectuation of inclusive process, and that the conceptions and educational practices point to the non accountability of professor by pedagogical activities with students with special educational needs. Finally, it was found that the Pibid can be a potential space for discussions and reflections on the actions and concepts inclusive.
\end{abstract}

Keywords: Scholar Inclusion; Special Needs Education; Special Education.

\title{
Resumen
}

Este trabajo tuvo como foco el entendimiento de las condiciones y perspectivas de inclusión en el municipio de Araras, a partir de los relatos de profesores, gestores y pibidianos2. La recolecta de datos se realizó por medio de la aplicación de cuestionarios y entrevistas semiestructuradas, buscando la comprensión de las concepciones de los agentes educacionales en lo que se refiere al proceso inclusivo y de cómo estas concepciones influencian sus prácticas pedagógicas. El estudio se pauta en el abordaje cualitativo de investigación en educación. La búsqueda por el entendimiento de la realidad local es de gran importancia para nortear las acciones y prácticas educacionales que puedan colaborar para efectuación del proceso inclusivo, con vistas a la construcción de una escuela democrática. Se constató que la formación docente aún es un punto nodal en la efectuación de este proceso, siendo que las concepciones y prácticas educacionales apuntan para la no responsabilización del profesor por las actividades pedagógicas con alumnos con necesidades educacionales especiales. Por fin, se verificó que el Pibid se configura como espacio potencial para discusiones y reflexiones sobre las acciones y concepciones inclusivas.

Palabras clave: Inclusión escolar; Necesidades Educacionales Especiales; Educación Especial. 


\section{Introdução}

A inclusão, atualmente, é discutida de forma ampla nos meios acadêmicos, sociais e políticos. Entretanto, encontra sérias dificuldades para sua execução efetiva, sendo necessária a compreensão de como se estabelece o processo inclusivo na busca de concretização do mesmo. O movimento pela inclusão social se atrelou à busca por uma sociedade que oferecesse as mesmas oportunidades a todos os indivíduos, na qual as peculiaridades individuais devem ser aceitas e reconhecidas. No Brasil, um dos setores de maior impacto para essa discussão foi o educacional, gerando, assim, mudanças tanto nas políticas públicas quanto nas concepções que permeiam as práticas escolares.

Não existe consenso ao se falar da educação inclusiva, diferindo tanto no âmbito acadêmico, quanto político e social. De forma que é importante ressaltar que o processo inclusivo depende não apenas da matrícula do aluno com necessidades educacionais especiais (NEE) na rede regular, pois a simples inserção do mesmo na escola não garante sua participação no processo de ensino-aprendizagem, podendo levar, inclusive, à inclusão marginal.

Sobre essa questão podemos destacar que, segundo Martins (2002), Amaral (2002) e Patto (2008) a contraposição entre inclusão e exclusão, tão discutida na atualidade, em especial no âmbito das políticas educacionais, não é pertinente aos sistemas capitalistas, principalmente nos países periféricos. Os autores destacam que o capitalismo tem como traço congênito o processo de exclusão, que exclui o indivíduo para incluí-lo de outra forma, precária e marginal. $\mathrm{O}$ mesmo fenômeno ocorre na escola, já que, diversas vezes, os alunos são inseridos em um ambiente estigmatizador e não adequado ao atendimento às suas necessidades, não participando, assim, do objetivo central da educação escolar, ou seja, a apropriação do conhecimento acumulado ao longo da história.

Outro ponto que precisa ser destacado refere-se ao fato de que, apesar de historicamente a educação especial ter se voltado às pessoas com deficiência, hoje a inclusão escolar não se destina apenas a tais indivíduos, mas, sim, a todos aqueles que apresentem uma NEE. As NEE foram definidas na Declaração de Salamanca, englobando diversos grupos que, por algum motivo, não usufruem dos bens sociais garantidos pela escola, tais como: pessoas com deficiência, populações nômades, crianças que trabalham ou moram nas ruas, entre outros.

Para Bueno (2008) devemos ter em mente que a inclusão de alunos com NEE no ensino regular depende, em grande parte, de professores que estejam preparados para o atendimento dos mesmos e que se estribem na perspectiva de diminuição gradativa da exclusão e inclusão marginal e da qualificação do rendimento do alunado; ao mesmo tempo em que, dentro dessa perspectiva, apropriem-se de conhecimentos e desenvolvam práticas específicas necessárias para a efetiva inclusão e não suas práticas perversas. 
Se nunca tivemos uma escola formadora da inteligência crítica, já tivemos uma escola que, pelo menos, ensinava a ler e a escrever. Hoje o ensino está, como regra, aquém até mesmo da pseudo-formação tal como entendida por Adorno. E aumentar, sem mais nada, a duração do ensino fundamental em mais um ano só aumentará a angústia dos que participam da vida escolar (MENDES, 2002, p.36).

Sendo assim, é certo que políticas e práticas que apenas encaminham as classes marginalizadas às instituições de ensino, de nada adiantam, visto que o direito e a concretização da aprendizagem não são garantidos.

Como forma de suporte complementar à matrícula na escola regular, o aluno com NEE pode frequentar o atendimento educacional especializado (AEE) que se configura como serviço de educação especial que identifica, elabora e organiza recursos pedagógicos e de acessibilidade que devem eliminar barreiras para a plena participação dos alunos, considerando suas necessidades específicas. Ele deve ser articulado com a proposta da escola regular, embora suas atividades se diferenciem das realizadas em salas de aula de ensino comum (MEC, 2009). Portanto, é preciso que se estabeleça um trabalho colaborativo e se desenvolvam práticas educacionais inclusivas, sendo que a formação inicial e continuada de professores que atuam na educação básica passa a ser um ponto nodal para a estruturação de ações inclusivas.

Outro ponto a ser destacado, trata-se da configuração da escola especial como espaço de atendimentos especializados, tal como proposto pela Política Nacional de Educação Especial na Perspectiva da Educação Inclusiva, de 2008. Esse entendimento trouxe uma nova forma de interpretação para a modalidade de educação especial, que não se concretizou no Decreto 7.611 de 2011, no qual a escolarização dos alunos volta a acontecer, preferencialmente, no ensino regular, abrindo espaço novamente a espaços segregados (BRASIL, 2008, 2011).

Tendo por base essas considerações, este estudo apresentou como objetivos:

- Analisar as condições do processo de inclusão escolar de alunos com NEE incluídos nas escolas do município de Araras, a partir do relato de professores, supervisores e pibidianos.

- Investigar as concepções de docentes e gestores acerca da inclusão escolar, população atendida por esse processo e práticas educacionais envolvidas no processo inclusivo, no que se refere às escolas municipais da cidade de Araras.

\section{Percurso Metodológico}

A pesquisa foi efetivada a partir da aplicação de questionários e realização de entrevistas com gestores educacionais, professores da rede municipal de ensino de Araras e 
discentes bolsistas do Programa Institucional de Bolsa de Iniciação à Docência (Pibid), sendo, então, elaborada análise qualitativa que buscou compreender as contradições e movimento dialético que está presente na concretização do processo inclusivo.

No município de Araras, existem 6 escolas municipais que possuem o segundo ciclo do ensino fundamental, entretanto, no momento da pesquisa apenas 3 dessas escolas eram atendidas pelo Pibid, sendo este o critério de seleção para a participação no estudo.

Esta pesquisa teve como informantes: 10 professores de 3 escolas municipais de Araras atendidas pelo Pibid, dentre os quais 3 são supervisores do Pibid; 3 representantes da Secretaria Municipal de Educação, vinculados à educação especial, e 6 licenciandos que fazem parte do Pibid da UFSCar - Araras.

A seleção dos sujeitos foi realizada mediante sorteio; todos os indivíduos sorteados foram informados que não havia obrigação de participar da pesquisa, podendo recusar-se tanto no início quanto no decorrer da mesma.

Foram utilizados os seguintes instrumentos: gravador digital, termo de consentimento livre e esclarecido, questionário, roteiro de entrevista semiestruturada, carta de informação ao sujeito de pesquisa.

Quanto aos procedimentos, obedeceram às etapas descritas:

- Sorteio dos participantes da pesquisa.

- Autorização das escolas e dos participantes para desenvolvimento da pesquisa.

- Elaboração e distribuição do questionário com questões fechadas e abertas para mapeamento dos alunos com NEE incluídos nas escolas municipais de Araras selecionadas e dos atendimentos recebidos por eles.

- Análise dos questionários.

- A partir da análise dos questionários, foi realizada a elaboração do roteiro de entrevistas semiestruturadas, com cinco eixos temáticos.

- Realização de projeto piloto para analisar a adequação do roteiro aos objetivos do projeto.

- Realização das entrevistas com os sujeitos da pesquisa.

- Transcrição e análise das entrevistas com base no referencial teórico.

\section{Resultados e Discussão}

Vivemos em um país no qual os direitos e deveres do homem são amparados por leis que abrangem o cenário educacional. Apesar do aparato legal, no que se refere aos alunos 
com NEE, garantir a participação no processo educacional, preferencialmente no ensino regular, ainda hoje leva-nos a depararmos com barreiras físicas e atitudinais que permeiam as instituições escolares e impactam na função social da escola, bem como na formação dos agentes educacionais.

Dessa forma, debruçamo-nos sobre as concepções e perspectivas dos participantes da pesquisa, a partir de cinco eixos temáticos discutidos a seguir.

\title{
Eixo 1: Concepções sobre inclusão e educação especial
}

Quando os professores da rede regular foram questionados acerca de suas concepções sobre o termo inclusão, de modo geral, eles responderam que:

\begin{abstract}
Inclusão pra mim é querer colocar todos dentro de uma sala de aula sem que haja descriminação, seja a criança que ela tem problema motor, problema psico, na área da neurologia, junto com pessoas normais. (...) Inclusão eu sei que é eu penso né, não tenho certeza, que é o aluno que tem alguma deficiência, seja mental, física, ele precisa se sentir inserido numa escola, ele tem que se sentir normal (INFORMANTE 1ER).
\end{abstract}

Como já apontado neste trabalho, a inclusão não se destina apenas aos indivíduos que possuem uma deficiência, mas a qualquer pessoa que apresente uma necessidade educacional especial. No entanto, olhando para a resposta dos professores da rede regular, notamos que ainda há dúvidas em relação ao termo inclusão, pois o aluno com NEE não tem que ser inserido e, sim, incluído, já que a mera inserção ou matrícula não garante a apropriação do conhecimento e a participação efetiva na cultura e nos bens sociais.

Diferente do que os professores da rede regular afirmaram, os pibidianos relataram, com relação à inclusão, que "seria abrir as portas, mais que antigamente, para uma pessoa com NEE, seria uma inclusão, mas tendo caminhos alternativos, deixando as pessoas num bem-estar lá dentro" (INFORMANTE 1P) e "então pra mim, inclusão é você dar pra pessoa igualdade de oportunidade, tanto na lei, como na prática (...)” (INFORMANTE 2P).

A partir de então, fica claro que os alunos com NEE devem fazer jus às mesmas condições de aprendizagem que um aluno considerado normal, necessitando, para tanto, de meios que satisfaçam suas necessidades de aprendizagem. Conforme apontado por Góes (2002) a partir dos pressupostos da Teoria Histórico Cultural, o aluno com deficiência necessita de recursos especiais para que suas limitações sejam compensadas e ele possa encontrar vias alternativas de desenvolvimento. Ao falarmos de inclusão escolar, cabe aos agentes educacionais, incluindo os professores, a providência desses recursos que visem à equiparação de oportunidades. 
Depreende-se que, para atender ao novo ideal de escola inclusiva, torna-se necessário que ocorram mudanças concernentes à formação de professores, já que os alunos com NEE têm direito às mesmas oportunidades que quaisquer outros discentes em uma escola regular, necessitando, assim, que as instituições estejam preparadas para suprir e atender suas particularidades.

Quando os professores da rede regular foram questionados sobre a educação especial, responderam, de forma unânime, que:

Educação Especial eu entendo assim, que é um tratamento entre professor especializado pra trabalhar com situações especializadas, especiais, então a Educação Especial, o nome já dá esse sentido, é uma educação um pouco mais superior que a gente esta acostumado a trabalhar em sala de aula comum (INFORMANTE 1ER).

E em relação ao AEE responderam que "o AEE antecipa as informações (...), então a gente recebe um parecer desse aluno, do trabalho que tem que ser feito" (INFORMANTE 3ER).

Já os pibidianos, no que se refere à educação especial, disseram que:

Eu acho que educação especial, eu entendo como sendo o caminho
alternativo para educação com pessoa que tem algum tipo de deficiência,
seria então um caminho alternativo, do mesmo jeito que nós temos a
formação de professores que é tida comum, nós temos que ter também a
educação especial, que é algo voltado para, não é segregação, não é diferente
não, é algo que é necessário para que ocorra aprendizagem para pessoas
com necessidades educacionais especiais, então é um caminho alternativo
pra que possibilite, facilite a integração desse grupo de pessoas a esse grupo
maior de pessoas que é considerada normais, então seria um caminho
alternativo que elas precisam percorrer para poder aprender
(INFORMANTE 3P).

E em relação ao AEE responderam que "É um profissional que vai na escola (...) vai só pra atender aquela criança (...)” (INFORMANTE 4P).

Como forma de suporte complementar à matrícula na escola regular, o aluno com NEE pode frequentar o atendimento educacional especializado (AEE), que se configura como serviço de educação especial que identifica, elabora e organiza recursos pedagógicos e de acessibilidade que eliminem barreiras para a plena participação dos alunos, considerando suas necessidades específicas. O AEE é imprescindível para apoiar a aprendizagem do aluno com NEE na sala de ensino regular, estabelecendo parceria entre o professor especializado e o professor do ensino regular. Os professores de educação especial devem atuar de forma 
colaborativa com o professor da classe comum para a definição de estratégias pedagógicas que favoreçam o acesso ao aluno, ao currículo e a sua interação no grupo, entre outras ações que promovam a educação inclusiva.

A educação especial pode, então, estar diretamente relacionada ao processo de inclusão escolar, pois o aluno com NEE deve frequentar o ensino regular, mas em seu período contraturno ele estará em um centro especializado ou em uma instituição especializada, onde terá atendimento específico para suas necessidades educacionais e de vida diária, de maneira que o ajude a desenvolver suas habilidades.

Como afirmado anteriormente, foi possível constatar dúvidas no que se refere à educação especial e ao AEE por parte dos professores da rede regular, mas tal confusão pode ser explicada por meio da fala das representantes da secretaria municipal de educação especial, que dizem:

\begin{abstract}
(...) a gente vem de uma escola, entre aspas né, que nunca teve como princípio básico, assim, tornar a inclusão de fato um mecanismo real, porque a gente vem de uma cidade que institucionaliza (...) é uma cidade altamente segregadora e que agora tem mudado aos poucos a questão de que a diversidade pode conviver (...) O que a gente preconiza é que esse aluno tenha o atendimento, que não seja uma inclusão invisível, por que se for para ter uma inclusão só para ele ficar lá de corpo presente é fácil (INFORMANTE 1EE).
\end{abstract}

Historicamente, a criança com deficiência tem sofrido com a discriminação e com o preconceito da sociedade, de forma que a atuação pautada em preceitos médico- pedagógicos contribuiu para que ocorresse a segregação entre o individuo com deficiência e a comunidade. Januzzi (2006) aponta que a educação das pessoas com deficiência tem sido, ao longo dos séculos, oferecida de forma segregada à sociedade, com a justificativa de que tal afastamento estava pautado na ideia de que esses indivíduos necessitavam de lugar calmo e tranquilo para se desenvolverem. Quando, na verdade, essa medida escondia a tentativa de proteger os membros da sociedade do contato com a diferença.

Por que essas crianças viveram segregadas em grande parte de nossa história? Ao analisarmos a evolução do atendimento à deficiência notamos que, desde o mundo antigo, existe uma tentativa de separação do que era considerado diferente ou desviante. Apesar de já termos evoluído muito, ainda nos dias de hoje notamos mecanismos segregatícios e perversos, como a inclusão precária ou o distanciamento do indivíduo com uma NEE de seu grupo social e cultural.

De modo que voltamos a chamar a atenção para o fato de que a inclusão escolar não se restringe à matrícula do aluno com NEE na rede regular, pois a simples inserção do mesmo na escola não garante a apropriação do conhecimento, podendo levar à inclusão marginal, conforme discutido anteriormente. 
Eixo temático 2: Conhecimento e entendimento sobre as políticas educacionais voltada ao processo inclusivo

De acordo com esse eixo temático, os informantes foram questionados acerca do conhecimento sobre políticas educacionais que tratem da inclusão ou da educação especial e, segundo os professores da escola regular, no que se refere às políticas inclusivas a maioria dos professores disseram não ter conhecimento das mesmas, pois "não são facilmente abordadas" (INFORMANTE 1ER) e " pra escola não chega. Eu acho que não faz falta. É bom a gente saber, porque você tem que saber onde você esta pisando, mas o trabalho da escola ele não muda" (INFORMANTE 4ER).

A falta de preocupação com os marcos legais que norteiam o processo inclusivo pode afetar, diretamente, as práticas escolares desses professores, já que os mesmos, muitas vezes, agem de modo descomprometido e alegam não ser de sua responsabilidade o desenvolvimento de práticas educacionais voltadas ao atendimento dos alunos com NEE, ampliando, ainda mais, os mecanismos perversos de inclusão marginal. Sabemos que a mera letra da lei não modifica concepções e práticas, contudo o conhecimento da mesma é indispensável para que tanto os professores quanto os próprios alunos com NEE, vendo-se como sujeitos de direito, possam buscar alternativas para a marginalização e a segregação.

Diferente dos professores da rede regular, os pibidianos disseram ter conhecimento das políticas de educação inclusiva, transmitido na faculdade. "Pelas aulas da professora, eu conheci algumas coisas, mas na realidade, encontrar isso dentro das escolas... (expressão fácil de dúvida)" (INFORMANTE 1P) e “(...) Eu sei que a política, ela vai estar dando direitos e algumas obrigações que a escola tem que seguir (Informante 4P).

A formação - inicial e continuada - dos professores da rede regular e especial não pode estar desvinculada dos marcos legais que norteiam a educação especial e inclusiva. Sendo necessário, para além do conhecimento, o comprometimento com a execução das leis e políticas educacionais com vistas à construção de uma escola democrática. Como já referido, conhecer as legislações que contemplam a educação inclusiva não garante que o processo de inclusão se efetive, ao contrário, visualizamos possíveis abismos entre o que as políticas colocam e o que, de fato, acontece na realidade. Porém, entendemos que a compreensão crítica das políticas e ações sobre a inclusão escolar é um aprendizado importante para a formação e prática docente, pois perpetua a discussão e análise do que ocorre na atualidade, ampliando, assim, a perspectiva de uma educação de qualidade.

No que tange ao entendimento das políticas de educação especial e educação inclusiva, as professoras da rede especial avaliam que "a proposta do MEC é muito distante" (INFORMANTE 2EE).

Segundo Mendes (2002), leis e declarações não garantem a efetividade do processo, pois são necessárias ações que sejam apropriadas. A lei proporciona um respaldo, e nem sempre está certa, mas requer tentativa e, consequentemente, acontecerão erros e acertos. 
Dessa forma, é preciso deixar de apenas discutir leis e declarações e passar a experimentar alternativas de implementação, pois as políticas, em primeira instância, precisam levar em conta a realidade do local e, nesse sentido, precisam ser elaboradas interpretações a partir das necessidades de cada município.

Eixo temático 3: Experiências, ações e práticas inclusivas no âmbito da escola regular e na educação especial

Apesar de os professores do ensino regular desconheceram as leis referentes à educação especial e, aparentemente, não buscarem o conhecimento das mesmas, ao serem questionados sobre a experiência com alunos com NEE e suas respectivas responsabilidades no desenvolvimento de estratégias pedagógicas com eles, a maioria dos professores disseram que já trabalharam com esses alunos, mas “em hipótese nenhuma, tanto é que nós não estamos preparados para isso, estou respondendo por mim, a gente não esta preparado para trabalhar com crianças especiais" (INFORMANTE 1ER).

Em relação à responsabilidade em desenvolver estratégias pedagógicas com os alunos com NEE, os professores colocam que: "A responsabilidade é dos dois lados, tanto do professor quanto do poder público" (INFORMANTE 1ER); "Eu acho que não, não tem tempo hábil pra isso e como você vai fazer isso com a classe heterogênea, eu acho que não, embora a gente faça né? Sim, mas eu acho que não seria obrigação do professor, mas é feito aqui" (INFORMANTE 5ER) e (...) “É impossível isso, humanamente é impossível” (INFORMANTE 1ER).

Estranhamente, notamos no discurso dos professores a falta de conhecimento e interesse político associada à não assunção de responsabilidades relativas às práticas educacionais direcionadas aos alunos com NEE. O que prevalece, não apenas nesta pesquisa, mas em diversos estudos sobre a formação docente, é a culpabilização de diversas esferas (poder público, aluno, escola) pela falta de atendimento educacional de qualidade conferido a esses alunos. Não estamos, aqui, negando as imensas dificuldades encontradas pelos agentes educacionais no cotidiano das instituições escolares, entretanto, após quase vinte anos da assinatura da Declaração de Salamanca, o jogo de culpabilizações precisa ser interrompido e o direito do aluno à apropriação do conhecimento precisa ser efetivado.

Falta preparo, mas sobram barreiras atitudinais e arquitetônicas na vida dos alunos com NEE. Cabe, sim, ao poder público suprir as necessidades da escola, mas cabe aos professores, diretores e funcionários lutar pela modificação das concepções de déficit e fracasso soberanas nas escolas.

Ao mesmo tempo em que os professores da escola regular perpetuam o discurso da falta de preparação para subsidiar o fato de não se responsabilizarem por estratégias educacionais de alunos com NEE, os pibidianos mostraram-se preocupados com sua formação inicial, pois o currículo da universidade não permite que o mesmo receba formação essencial para atender esses alunos. "Se o aluno estiver na minha sala, sim, eu vou estar ali, eu vou ter 
que suprir a necessidade dele" (INFORMANTE 5P) e "(...) eu sei que to saindo daqui não formada pra suprir todas as necessidades educacionais que eu vá enfrentar (...)" (INFORMANTE 4P).

É de extrema importância a presença de profissionais comprometidos e devidamente capacitados, que proporcionem envolvimento com o processo inclusivo para que, aos poucos, as falhas e dificuldades enfrentadas nos dias atuais possam ser superadas. Sabe-se que essa mudança não acontecerá de forma rápida, ou seja, requer tentativas que ultrapassem a mera discussão dos dispositivos legais e busquem implementar experiências que favoreçam a efetivação da inclusão.

No que se refere às ações e práticas inclusivas desenvolvidas no município de Araras, em relação aos atendimentos educacionais especializados, as professoras de educação especial disseram que:

[...] todos os deficientes da rede, ou eles iam ou para essa escola que chamava "LH" ou para essa que chamava DADV. Isso era automático, mais ou menos assim. Então quando a gente chegou na rede, a cultura era essa, então elas eram fortes. Inclusive o aluno era primeiro alfabetizado e depois que ele ia para a rede regular. Então o processo não acontecia na escola regular. E então aqueles que não se conseguia alfabetizar o que acontecia: Não iam. Então a gente tinha esse mecanismo, que aos poucos, quando a gente foi entrando, a gente foi, junto com a política né (os avanços na política nacional), a gente foi tentando mexer isso [...]. Em 2008, abriu uma escola, e nós fizemos o que fizemos que foi aberto o centro. Então, quem está no centro, hoje, [...] são aqueles ou que não têm condições no mercado competitivo, que a gente sabe também que o mercado, embora tenha as cotas, ele quer que necessariamente seja quem tem condição, então acaba ficando excludente do mesmo jeito, e alguns casos mais sérios, autismo ou múltiplas com necessidade de cuidador mais em tempo integral. O professor não quer fazer parte do processo, não consegue ver a diferença como uma opção de enriquecimento para ele, até para as práticas dele. Então a gente lida com isso diariamente, com essa resistência, porque é muito complicado (INFORMANTE 1EE).

Mendes (2006) discute em seu texto as bases do surgimento da normalização no Brasil, visto que a pessoa com deficiência era encaminhada para a escola especial para ser normalizada, ou seja, para ser curada e, posteriormente, adaptada no ensino regular. Este ideal de normalização é completamente contrário à ideia inicial de normalizar as condições de vida e não a pessoa. Mesmo fugindo a esse ideal, verificamos, no cotidiano, que os professores do ensino regular apresentam uma tendência por se eximir do processo inclusivo, apoiados em justificativas de déficit de formação, como discutimos a seguir, e que trazem para suas práticas a tentativa de adaptação do aluno com NEE às características da escola, sem se preocupar com as vias alternativas de aprendizagem e desenvolvimento necessárias aos mesmos. 


\section{Eixo temático 4: Formação de professores}

No que concerne à formação de professores, segundo o artigo 18 da resolução CNE/CEB $\mathrm{n}^{\circ}$ 2, de 11 de fevereiro de 2001, para atender alunos com NEE os professores precisam ser capacitados ou especializados. O professor capacitado deve ter sua formação em nível médio ou superior e o professor especializado deve ter sua formação em nível superior ou em pós-graduação. Ambos os professores (capacitados e especializados) devem desenvolver atividades pedagógicas em conjunto, de maneira que o professor capacitado, quando está atuando em sala de aula regular, use dessas práticas para favorecer o processo de ensino-aprendizagem e possa contar, caso tenha alguma dúvida ou dificuldade, com o professor especializado. $\mathrm{O}$ trabalho colaborativo entre o professor de educação especial e o professor da sala regular é de grande importância para favorecer a inserção dos alunos com NEE no processo, cumprindo o papel social da escola tal como proposto por Saviani (2010).

Entretanto, a existência dessa divisão na formação docente é analisada por Michels (2006) como perpetuadora de ambiguidade, pois a legislação separa o professor capacitado do professor especializado, surgindo, assim, a cisão do trabalho pedagógico dentro da escola, com o agravante de que esses professores não estão se encontrando para discutir as questões pertinentes à educação dos alunos com NEE.

A própria lei, ao fragmentar os atendimentos educacionais, de certa forma exime de responsabilidades o professor da sala regular, e, por isso, muitos professores alegam que o aluno com NEE não é de sua responsabilidade e, sim, da escola especial ou do AEE.

Devido a isso, e à fala dos professores expostas anteriormente, foi perguntado para os profissionais da sala regular quais os tipos de cursos e formação específica eles receberam para atuar com os alunos com NEE. Obtivemos as seguintes respostas:

[...] nós professores não estamos preparados, talvez se tivesse um preparo melhor para atender esses alunos seria mais fácil pra gente (INFORMANTE 6ER).

Eu acredito assim, quem sai da faculdade hoje, a gente vê às meninas que vem fazer estágio a gente até fala assim pra elas, vocês estão vendo a realidade aqui na sala de aula hoje, talvez o profissional se forme ele não vai mais querer trabalhar na educação, tem que estar vendo tudo isso, porque a própria formação dele da graduação esta muito distante da realidade da escola, ele é formado pra um conteúdo, talvez as universidades e as faculdades são muito conteúdistas, então quando eles chegam aqui eles vão ver que a realidade é outra (INFORMANTE 4ER).

Ao pensarmos na formação inicial, é notório que, para a formação ideal de um professor capacitado, o currículo das universidades, muitas vezes, não atende às demandas 
necessárias para atuar com alunos com NEE, conforme destacado nas falas de todos os pibidianos, como por exemplo:

[...] teria que ter uma mudança no currículo, alguma coisa que pudesse, porque se ta na lei que o aluno pode ir pra escola regular e nós vamos ser professores da escola regular, então a gente tem que ter disciplinas que capacitasse melhor pra poder atender. Entre a lei e o que ta sendo feito na educação superior, tem uma discordância né? Porque se a lei fala que o aluno especial pode estar na rede regular, eu vou ter que estar preparado pra atender esse aluno (INFORMANTE 2P).

O investimento na formação inicial é essencial para a mudança do cenário atual da educação inclusiva, pois ao saírem dos cursos de licenciatura com um olhar crítico para os processos de aprendizagem e desenvolvimento de pessoas com NEE, os professores poderão começar a modificar os discursos de falta de preparação e responsabilização em busca de uma efetiva inclusão escolar.

A partir do discurso de falta de preparação, tão candente nos professores do ensino regular do município, foi questionado às professoras de educação especial as formas de capacitação e formação continuada disponibilizadas pela secretaria municipal de educação. Foram destacados tanto cursos oferecidos pela secretaria, como incentivo a afastamento para a pós-graduação, entretanto, segundo as entrevistadas, existe pouco interesse por parte dos professores.

\section{Eixo temático 5: Contribuição do Pibid para o processo de inclusão.}

Uma das maneiras de ter contato com a realidade do ensino regular é a participação do licenciando no Pibid, pois o referido programa pode iniciar a relação entre discente e a educação básica, proporcionando ao primeiro as experiências que podem ser ressignificadas ao longo de sua formação inicial e continuada.

Partindo desse pressuposto, os pibidianos foram questionados acerca da contribuição do programa no entendimento do processo inclusivo e desenvolvimento de estratégias pedagógicas voltadas aos alunos com NEE. Em geral, as respostas relataram que:

Eu acho que contribui, porque pelo simples fato do PIBID proporcionar uma experiência prévia, antes de estar formado, você acabou de sair da faculdade, você vai pra escola, você não conhece nada da escola é uma coisa agora quando você já tem um PIBID no seu currículo isso te ajuda muito, porque você já viu como funciona dentro da escola, já que as escolas ágoras são inclusivas, você já viu pessoas com deficiência, com Necessidades 
Educacionais Especiais dentro da escola, então você já tem algo, como que é, já sabe como os professores lidam (INFORMANTE 3P).

O Pibid pode contribuir muito para a formação inicial do licenciando, proporcionando uma oportunidade à contextualização do cotidiano escolar. O programa, no âmbito de formação dos futuros professores, é de grande importância, tanto no que se refere à compreensão dos fenômenos que permeiam as práticas educativas, quanto na busca pela modificação de práticas escolares que favorecem as práticas perversas de inclusão. Ao ter contato com a realidade educacional ao longo de sua formação inicial, favorece-se o entendimento de como a formação universitária pode contribuir para a constituição de docentes críticos e autônomos. Além disso, para que se proponham ações que garantam a efetiva inclusão dos alunos com NEE no processo de aprendizagem, é preciso, primeiro, conhecer as condições educacionais nas quais se encontram.

Diferente do que os pibidianos dizem, os professores que conhecem o projeto Pibid dizem que “(...) até que pode, mas eu acho assim, eles também não têm essa bagagem pra entender" (INFORMANTE 5ER) e "só a integração que eles proporcionam já é positiva, porque eles têm uma interação legal entre os alunos. (...) a gente percebe assim, a interação, a integração dos alunos é bastante positiva com esses alunos, acho que pro deficiente já é um pouco positivo isso" (INFORMANTE 3ER).

A vivência no Pibid pode oportunizar que os licenciandos tenham visão mais ampla do que é a inclusão, como os alunos com NEE estão sendo tratados dentro da sala de aula regular e até mesmo na escola; então, isso faz com que eles adquiram uma formação com um olhar mais crítico e reflexivo no que tange aos desafios de implantação de uma escola realmente inclusiva.

Notamos, ao longo das entrevistas e relatos dos informantes, que, em geral, os licenciandos estão mais abertos e preparados para lidar com o fenômeno da inclusão escolar do que muitos professores e supervisores do próprio Pibid. Podemos pensar que, apesar de não possuírem na grade curricular disciplinas voltadas à educação inclusiva, os discentes têm privilegiado a discussão crítica acerca da inclusão de alunos com NEE, tanto na esfera universitária como nas próprias ações desenvolvidas como bolsistas do Pibid.

\section{Considerações finais}

Diante dos dados discutidos, podemos observar que os professores do ensino regular e os supervisores do Pibid ainda entendem de forma superficial o processo de inclusão escolar, sendo que mesmo de maneira latente a maioria deles tentam se isentar da responsabilidade de desenvolver práticas pedagógicas com alunos com NEE, culpabilizando o déficit em suas formações e as políticas governamentais implantadas de modo ineficiente. Não podemos 
desconsiderar as mazelas da profissão docente, tão sucateada ao longo da história brasileira, mas também não é mais possível fechar os olhos para o fato de que grande parte dos professores da escola regular esconde-se nessas mazelas, justificando práticas perversas de inclusão e segregação.

De acordo com a Secretaria Municipal de Educação da cidade de Araras, são realizados cursos de capacitação para esses professores, juntamente com cursos de outras áreas, sendo que os professores demonstram pouco interesse na temática inclusiva e buscam cursos vinculados à sua disciplina. Sendo assim, fica difícil o professor ter curso de capacitação inclusiva, uma vez que optam por deixam de lado essa temática e continuam na zona de conforto da não formação.

Diferente dos professores do ensino regular, é possível notar que os licenciandos sabem que é de sua responsabilidade desenvolver atividades dentro da sala de aula com os alunos com NEE, mas têm a consciência que sua formação inicial não garantirá que tenham as devidas condições para desenvolver essas atividades no processo inclusivo.

É muito importante que no ensino regular se tenha a presença de profissionais comprometidos e com formação adequada às necessidades do alunado, que proporcionem envolvimento com o processo inclusivo para que, aos poucos, as falhas e dificuldades enfrentadas nos dias atuais possam ser superadas. Sabe-se que se trata de uma mudança que demanda tempo e investimento, sendo importante ir além das discussões sobre os dispositivos legais e buscar implementar experiências que favoreçam a efetivação da inclusão. Esse

processo pode começar dentro das universidades, de forma a melhorar a formação dos licenciandos.

A realidade da inclusão no município de Araras parece depender, ainda, de trabalhos em equipe, nos quais todo o grupo escolar se sinta responsável pela inclusão dos alunos com NEE e não delegando exclusivamente ao professor regular ou ao professor da escola especial ou AEE.

Por fim, consideramos que o processo inclusivo não pode ser mais ignorado, sendo que podemos notar avanço nas pesquisas e na legislação, mostrando que é possível que os sujeitos com NEE sejam incluídos. Precisamos romper com o sistema excludente, efetivando o acesso e a qualidade na educação para todos, abrindo as portas para escolas mais democráticas e favorecendo, assim, que todos realmente tenham a oportunidade de aprender e se desenvolver. Então, a inclusão de sucesso é aquela que conta com a colaboração de todos os envolvidos no processo, criando ambiente estimulador e desenvolvendo habilidades criativas de solução de problemas, promovendo o apoio mútuo e o compartilhamento das responsabilidades na escolarização dos alunos com NEE.

\section{Referências}

AMARAL, L. A. Diferenças, estigma e preconceito: O desafio da inclusão. In: OLIVEIRA, M. K.; SOUZA, D.T.R.; REGO, T.C. (Orgs). Psicologia, educação e as temáticas da vida contemporânea. São Paulo: Moderna, 2002. p. 233-24. 
BRASIL. Resolução CNE/CEB No 2, de 11 de Fevereiro de 2001. Dispõe sobre as Diretrizes Nacionais de Educação Especial na Educação Básica. Disponível em:

http://portal.mec.gov.br/seesp/arquivos/txt/res2.txt>. Acesso: em 31 out. 2012.

BRASIL. Ministério da Educação. Secretaria de Educação Especial. Política Nacional de Educação Especial na Perspectiva da Educação Inclusiva. Disponível em:

<http://portal.mec.gov.br/arquivos/pdf/politicaeducespecial.pdf>. Acesso em: 18 ago. 2015. 2008 - inserir

BRASIL. Casa Civil. Decreto 7.611, de 17 de novembro de 2011. Dispõe sobre a educação especial, o atendimento educacional especializado e dá outras providências. Disponível em: <http://www.planalto.gov.br/ccivil_03/_ato2011-2014/2011/decreto/d7611.htm>. Acesso em: 18 ago. 2015.

BUENO, J.G.S. As políticas de inclusão escolar: uma prerrogativa da educação especial? In: ; MENDES,G.M.L.; SANTOS, R.A. Deficiência e escolarização: novas perspectivas de análise. Araraquara: Junqueira e Marin; Brasília: CAPES, 2008. p. 43-63.

GÓES, M.C.R. Relações entre desenvolvimento humano, deficiência e educação: contribuições da abordagem histórico-cultural. In: OLIVEIRA, M.K.; SOUZA, D.T.R.; REGO, T.C. Psicologia, educação e as temáticas da vida contemporânea. São Paulo: Moderna, 2002, p. 95-114

JANUZZI, G.M. A educação do deficiente no Brasil dos primórdios ao início do século XXI. 2ed. Campinas: Autores Associados, 2006.

MARTINS, J.S. A sociedade vista do abismo: novos estudos sobre exclusão, pobreza e classes sociais. 2 ed. Petrópolis: Vozes, 2002.

MINISTÉRIO DA EDUCAÇÃO - MEC. Resolução CNE/CEB 04, de 02 de outubro de 2009. Institui Diretrizes Operacionais para o Atendimento Educacional Especializado na Educação Básica, modalidade Educação Especial. Disponível em:

<http://portal.mec.gov.br/dmdocuments/rceb004_09.pdf>. Acesso em: 01 mar. 2013.

MENDES, E.G. Perspectivas para a construção da Escola Inclusiva no Brasil. In:

PALHARES, M.S.; MARINS, S.C.F. (Orgs). Escola Inclusiva. São Carlos: EdUFSCar, 2002. p. 61-85.

MICHELS, M. H. Gestão, Formação Docente e Inclusão: eixos da reforma curricular educacional brasileira que atribuem contornos a organização escolar. Revista Brasileira de Educação, Rio de Janeiro, v. 11, n. 33, p.406-423, Set./Dez, 2006. 
PATTO, M.H.S. Políticas atuais de inclusão escolar: Reflexão a partir de um recorte conceitual. In: BUENO, J.G.S.; MENDES, G.M.L.; SANTOS, R.A. Deficiência e escolarização: novas perspectivas de análise. Araraquara: Junqueira e Marin; Brasília: CAPES, 2008. p.25-42.

SAVIANI, D. Organização da Educação Nacional: sistema e conselho nacional de educação, Plano e Fórum Nacional de Educação. Revista Educação e Sociedade, Campinas, v. 31, n. 112, p. 769-787, Jul./Set. 2010.

Recebido em: 22/07/2013

Revisado em: 14/11/2013

Aprovado para publicação em: 13/12/2013

Publicado em: 31/08/2015 